\title{
Using the National Population Health Survey to Identify Factors Associated with Patterns of Psychological Distress Over 10 Years
}

Définir les facteurs associés aux cycles d'épisodes de détresse sur une période de dix ans à l'aide de l'Enquête nationale sur la santé de la population

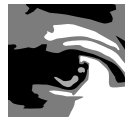 \\ by HEATHER M. ORPANA, PHD \\ Statistics Canada E School of Psychology, University of Ottawa \\ Ottawa, ON
}

\begin{abstract}
Objective: To use longitudinal data to group individuals based on their pattern of episodes of high distress, and to identify the socio-demographic correlates of these groups as well as their healthcare utilization.

Data Sources/Study Design: The National Population Health Survey (NPHS) was used to study 15,254 individuals over a period of 10 years from 1994/95 to 2004/05. We examined the socio-demographic correlates and healthcare utilization of different distress pattern groups.
\end{abstract}


Principal Findings: Significant differences between the no distress, single and multiple distress episode groups were observed on both socio-demographic characteristics and healthcare utilization.

Conclusions: Data about the same individuals over time provide better information than data collected at a single point in time. This information can be used to improve planning and provision of mental healthcare services.

\section{Résumé}

Objectif: Utiliser des données longitudinales pour regrouper des individus selon la tendance de leurs cycles d'épisodes de détresse aiguë, pour dégager des corrélats sociodémographiques au sein de ces groupes et pour connaitre leur utilisation des services de santé.

Sources de données/conception de l'étude: L'Enquête nationale sur la santé de la population (ENSP) a suivi 15254 individus sur une période de dix ans entre 1994-1995 et 2004-2005. Nous avons étudié les corrélats sociodémographiques et examiné l'utilisation des services de santé de divers groupes définis selon la tendance de leurs cycles d'épisodes de détresse.

Principaux résultats : Nous avons observé des différences significatives entre les divers groupes (sans épisode de détresse, avec un seul épisode de détresse, avec plusieurs épisodes de détresse) tant sur le plan des caractéristiques sociodémographiques que sur celui de l'utilisation des services de santé.

Conclusion: On obtient une meilleure information à partir de données portant sur les mêmes personnes pendant une période de temps quà partir de données recueillies de façon ponctuelle. Cette information peut être utilisée afin d'améliorer la planification et la prestation des services de santé mentale.

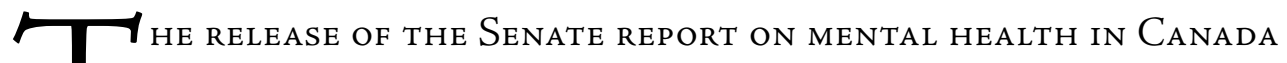

(Kirby and Keon 2006) and the 2007 funding announcement of a National

Lental Health Commission (Government of Canada 2007) have recently intensified the focus on mental health. According to the Canadian Community Health Survey, in 2002, 1.2 million Canadians had a major depressive episode, nearly 750,000 were affected by social anxiety disorder, 376,000 experienced panic disorder and 239,000 had a manic episode (Statistics Canada 2004). By the year 2030, unipolar depressive disorder is expected to be the leading contributor to disability-adjusted life years (DALYs), accounting for almost 10\% of DALYs in high-income countries (Mathers and Loncar 2006).

Much mental health research has been based on the Canadian Community 
Health Survey on the Mental Health and Well-being of Canadians, but few researchers have exploited the potential of the longitudinal National Population Health Survey (NPHS) (Tambay and Catlin 1995) to examine patterns of mental health and mental illness within the same individuals over time. Longitudinality is important because patterns of incidence, recurrence and chronicity of mental disorders, especially major depressive disorder and anxiety disorders, may characterize distinct subtypes of these diseases (DeMarco 2000; Angst et al. 2007). In turn, these subtypes may be associated with different risk factors, treatment options and patterns of healthcare utilization (Sareen et al. 2005; Rhodes and Fung 2004).

Psychological distress is a non-specific negative state of mental health, comprising symptoms of both depression and anxiety. Although distress is generally measured on a continuum, thresholds can be identified to indicate probable mental illness (Cairney et al. 2007; Kessler et al. 2002; Furukawa et al. 2003). This study utilizes 10 years of NPHS data to describe individuals who experience no, single and multiple observed episodes of high psychological distress over six periods of observation, and to describe their use of mental healthcare services.

\section{Methods}

This analysis is based on data from cycles 1 to 6 of the longitudinal National Population Health Survey (NPHS), conducted by Statistics Canada from 1994/1995 to $2004 / 2005$ (Tambay 2005). Every two years since 1994/1995, the NPHS has collected data about health status, health behaviours and other determinants of health. This survey is representative of the household population in all provinces in 1994/1995, excluding members of the regular Canadian Forces and residents of Indian reserves, Crown lands, health institutions, some remote areas in Ontario and Quebec and Canadian Forces bases.

The response rate for the initial cycle was $86 \%$, yielding 17,276 respondents. By $2004 / 2005,32.9 \%$ of respondents had been lost to attrition. More detailed descriptions of the NPHS design, sample and interview procedures are available in other papers and reports (Tambay and Catlin 1995). This analysis is based on respondents aged 12 or older, resulting in a sample size of 15,254 .

Distress was measured using respondents' scores on the K6, a psychological distress measure developed by Kessler et al. (2002), which has been used in numerous population-based surveys. The K6 measures distress through answers to six Likert-type questions scored from 0 to 4 , which are summed to form a scale score with potential total scores ranging from 0 to 24 . Questions refer to feelings such as nervousness or depressed mood over the past month, and include items such as "During the past month, ... about how often did you feel tired out for no good reason?" and "During the past month, ... about how often did you feel sad or depressed?" Based 
on previous analyses comparing the $\mathrm{K} 6$ score to 12 -month anxiety disorder or major depressive disorder, a score of 9 or more was considered to indicate high psychological distress and a possible mood or anxiety disorder (Orpana et al. in review).

Respondents were classified into three groups based on their patterns of distress over the six survey cycles. Those who had low distress scores $(\leq 8)$ at each cycle in which they participated were assigned to the "no observed distress" group. Those who experienced a single episode of high distress (a score $\geq 9$ ) were placed in the "single observed episode" group, and those who experienced two or more episodes of high distress were assigned to the "multiple observed episodes" group. Thus, respondents did not need to participate in each survey cycle to be included in the analysis.

Respondents' sex, age group (12-18, 19-34, 35-54, 55 years and older), employment status, marital status, household income quintile, immigration status, province of residence and urban/rural status in 1994/1995 were used as co-variates. Whether respondents reported consulting a healthcare professional about their mental or emotional health in the past year, and how many times they had done so, were measured at each cycle.

\section{Analysis}

The proportion of respondents experiencing single and multiple observed episodes of high distress was computed, as was the proportion in each group (no distress, single observed episode, multiple observed episodes) consulting a health professional about their mental or emotional health in the past year. The mean number of contacts in the past year among those who did consult a health professional about their mental or emotional health was also computed. Because of the likely effect of currently experiencing high distress on the probability of having seen a health professional and on the number of visits, the analyses were stratified by whether respondents were experiencing high distress during a given cycle. The socio-demographic correlates of belonging to the single-episode or multiple-episode groups were analyzed using multinomial logistic regression in SUDAAN (2007), comparing the single- and multiple-episode groups to the no-episode group. Confidence intervals (CIs) were calculated using the bootstrap method (Rust and Rao 1996).

\section{Results}

While a large majority (81.4\%) (95\% CI 80.6-82.2) of the 1994/1995 cohort experienced no observed episodes of high distress over the six periods of follow-up, $11.1 \%$ (95\% CI 11.1-12.4) experienced a single episode and 6.8\% (95\% CI 6.4-7.3) experienced multiple episodes of high distress. Based on these estimates, more than 1.6 million Canadians who were aged 12 and over in 1994/1995 experienced at least two 
episodes of high distress in the past 10 years, and almost three million more experienced at least one episode. Because distress was measured for only six one-month periods over the 10 years of the study, these estimates of the prevalence of distress are likely understated.

Women were almost 50\% more likely than men to experience a single observed episode of distress and twice as likely to experience multiple observed episodes (Table 1). People younger than 55 were significantly more likely than those 55 or older to experience single and multiple episodes of distress. Compared with people who were married, single and previously married (widowed/divorced/separated) individuals were more likely to experience both single and multiple episodes of distress.

TABLE 1. Adjusted odds ratios relating socio-demographic characteristics to single and multiple observed episodes of high distress over 10 years, 1994/I995-2004/2005

\begin{tabular}{|c|c|c|}
\hline \multirow[t]{2}{*}{ Characteristic in 1994//995 } & \multirow{2}{*}{$\begin{array}{l}\text { Single } \\
\text { Adjusted OR }(95 \% \mathrm{Cl})\end{array}$} & \multirow{2}{*}{$\begin{array}{l}\text { Multiple } \\
\text { Adjusted OR }(95 \% \mathrm{Cl})\end{array}$} \\
\hline & & \\
\hline \multicolumn{3}{|l|}{ Sex } \\
\hline $\mathrm{Male}^{\dagger}$ & 1.00 & 1.00 \\
\hline Female & 1.46*(1.26, 1.68) & $2.00 *(1.63,2.45)$ \\
\hline \multicolumn{3}{|l|}{ Age } \\
\hline 12 to 18 & $2.29 *(1.61,3.27)$ & $1.85 *(1.17,2.92)$ \\
\hline 19 to 34 & 1.73* (1.33, 2.24) & $2.37 *(1.78,3.17)$ \\
\hline 34 to 54 & $1.70 *(1.37,2.12)$ & $2.52 *(1.92,3.31)$ \\
\hline 55 or older $^{\dagger}$ & 1.00 & 1.00 \\
\hline \multicolumn{3}{|l|}{ Employment status } \\
\hline Employed $^{+}$ & 1.00 & 1.00 \\
\hline Not currently working & $1.45 *(1.13,1.86)$ & $1.34(0.94,1.92)$ \\
\hline Not working past 12 months & $1.42 *(1.16,1.74)$ & 1.60* $(1.27,2.02)$ \\
\hline \multicolumn{3}{|l|}{ Marital status } \\
\hline Married/living with a partner ${ }^{\dagger}$ & 1.00 & 1.00 \\
\hline Single & 1.32* (1.07, 1.63) & $1.44 *(1.12,1.84)$ \\
\hline Separated/Divorced/Widowed & 1.28*(1.04, 1.56) & $1.77 *(1.36,2.31)$ \\
\hline \multicolumn{3}{|l|}{ Household income quintile } \\
\hline Lowest income & $1.61 *(1.25,2.06)$ & $2.55 *(1.77,3.67)$ \\
\hline Low-mid & $1.54 *(1.23,1.92)$ & $1.69 *(1.17,2.43)$ \\
\hline
\end{tabular}


TABLE 1. Continued

\begin{tabular}{|l|l|l|}
\hline Middle income & $1.15(0.90,1.46)$ & $1.48 *(1.05,2.10)$ \\
\hline Mid-high & $1.20(0.96,1.49)$ & $1.33(0.92,1.92)$ \\
\hline Highest income $^{\dagger}$ & 1.00 & 1.00 \\
\hline Immigration status & & \\
\hline Born in Canada† & 1.00 & 1.00 \\
\hline Immigrant to Canada & $1.21 *(1.01,1.45)$ & $0.98(0.73,1.31)$ \\
\hline Region & & \\
\hline Atlantic & $0.87(0.74,1.02)$ & $1.00(0.76,1.32)$ \\
\hline Quebec & $1.31 *(1.07,1.61)$ & $1.36 *(1.08,1.71)$ \\
\hline Ontario† & 1.00 & 1.00 \\
\hline Prairies & $1.03(0.85,1.25)$ & $0.95(0.74,1.21)$ \\
\hline British Columbia & $1.10(0.87,1.39)$ & $0.85(0.62,1.17)$ \\
\hline Rurality & & 1.00 \\
\hline Urban† & 1.00 & $0.79(0.62,1.02)$ \\
\hline Rural & $0.87(0.74,1.02)$ & $0.62 *(0.50,0.75)$ \\
\hline Any missing cycle & $0.95(0.81,1.11)$ & \\
\hline
\end{tabular}

† Reference category.

* Significantly different for estimate from reference category $(p<, 05)$.

Source: 1994/1 995 to 2004/2005 National Population Health Survey, longitudinal health file.

A clear income gradient in the likelihood of experiencing distress emerged. For example, residents of households in the lowest income quintile were over twice as likely to experience multiple episodes of distress and more than $50 \%$ more likely to experience a single episode, compared with people in the highest income quintile. Compared with employed people, those who had not worked in the past 12 months, or who had worked during that time but were not currently working, were significantly more likely to experience a single episode of distress. Only those who had not worked in the past 12 months were significantly more likely to experience multiple episodes of distress.

Immigrants were marginally more likely to experience a single, but not multiple, episode of high distress than were people born in Canada. No differences were observed between urban and rural residents. However, Quebec residents were 31\% more likely to experience a single episode of distress, and 36\% more likely to experience multiple episodes, than were Ontario residents. No other significant regional differences were observed. 
A relatively low proportion of individuals in the no-episodes group reported having consulted a health professional for mental or emotional health reasons at each of the six cycles; approximately $5 \%$ of them had used such a resource during the previous year (Table 2), with an average of close to seven visits. In contrast, even when not distressed, $15 \%$ of individuals in the multiple-episodes group consulted a health professional about their mental health, with significantly more visits than those who were never distressed (10.1 vs. 6.6 visits). During cycles when they reported high distress, $35 \%$ of the multiple-episode group reported consulting a mental healthcare professional, with an average of over 14 visits.

TABLE 2. Percentage consulting a health professional about mental/emotional health and average number of contacts ${ }^{\dagger}$ in the past year, by distress group and current distress (data pooled over 6 cycles)

\begin{tabular}{|l|l|l|l|l|l|l|}
\hline & \multicolumn{2}{l}{ Not distressed } & \multicolumn{2}{l|}{ Distressed } \\
\hline & $\%$ & Mean visits & (SE) & $\%$ & Mean visits & (SE) \\
\hline Never distressed & 5 & 6.6 & 0.5 & $\mathrm{n} / \mathrm{a}$ & $\mathrm{n} / \mathrm{a}$ & $\mathrm{n} / \mathrm{a}$ \\
\hline Single episode & 11 & 7.2 & 0.6 & 26 & 10.5 & 1.0 \\
\hline Multiple episodes & 15 & 10.1 & 0.9 & 35 & 14.2 & 1.0 \\
\hline
\end{tabular}

${ }^{\dagger}$ Of those reporting consultation.

SE - Standard error.

n/a - Not applicable.

Source: 1994/1995 to 2004/2005 National Population Health Survey, longitudinal health file.

For those in the single-episode group who reported high distress at a given cycle, the proportion consulting a healthcare professional was $26 \%$, and the average number of times they had done so was over 10 . Not surprisingly, for both the single- and multiple-episode groups, the mean number of visits was significantly higher during cycles when they were experiencing high distress.

\section{Discussion}

Over the 10-year period from 1994/1995 to 2004/2005, the vast majority of Canadians studied did not experience an observed episode of high distress. However, an important number experienced single or multiple episodes of distress at levels likely to be clinically relevant (Cairney et al. 2007; Orpana et al. in review). Certain characteristics, such as being female, younger or previously married, as well as having low income and not being employed, were associated with a higher likelihood of experiencing either single or multiple episodes of high distress.

With respect to mental healthcare utilization, it is clear that those in the multiple-episodes group are higher users of mental healthcare services, even during periods 
when they are not experiencing high distress. This finding may indicate that this group has more chronic mental health problems that require ongoing contact with mental health professionals. However, the findings also reveal a large unmet need for mental healthcare: $65 \%$ of the multiple-episode group and $75 \%$ of the single-episode group who had experienced high distress during the previous month had not consulted a health professional about their mental or emotional health during the past year. This finding is similar to the estimated 64\% of individuals in the United States whose level of psychological distress indicates probable serious mental illness, but who do not have contact with a mental healthcare professional (Mojtabai 2005).

The primary limitations of this study are the time of measurement and respondent attrition. Because the distress measure in the NPHS refers to the past month, the identification of respondents who experienced high distress reflects six one-month periods of observation over 10 years. It is probable that some respondents experienced high distress at times when they were not observed. However, because six observations were used to categorize respondents into distress pattern groups, these groups reflect a richer gathering of information than would have occurred with a cross-sectional study. The prevalences reported cannot be interpreted to reflect the prevalence of experiencing high distress over 10 years, but should be interpreted as the prevalence of experiencing high distress one or more times during six one-month observation periods. The differences in socio-demographic characteristics and in mental healthcare use between those experiencing no, single or multiple episodes of distress indicate that this classification has some degree of validity.

Differential respondent attrition could also bias the results, especially because missing one or more cycles decreases the chances of observing an episode of high distress, and because distress may be related to being a missing respondent. While those who had missed one or more cycles were no less likely than those who missed none to be classified in the single-episode group, they were only $64 \%$ as likely to be classified in the multiple-episode group. However, including a variable indicating whether a respondent missed none versus any cycles did not change the relationships between socio-demographic correlates and group membership.

Despite these limitations, the use of the K6 psychological distress scale in this longitudinal study demonstrates the usefulness of multiple measurements of the same individuals over a long period of time in clarifying patterns and correlates of mental health problems. Further research should investigate more fully the subtypes of patterns of psychological distress and their predictors, including how changes to these predictors affect patterns of distress. Moreover, characteristics of distressed individuals who do not have contact with a mental healthcare professional should be explored further in order to identify vulnerable subgroups. Given the number of people who experienced episodes of high distress over a 10-year period, such findings may help to improve the mental health of a sizable number of Canadians. 
Using the National Population Health Survey to Identify

Factors Associated with Patterns of Psychological Distress Over 10 Years

Correspondence may be directed to: Heather Orpana, Statistics Canada, 100 Tunney's Pasture Driveway, Ottawa, ON K1A 0T6; tel: 613-951-1650; e-mail: Heather.Orpana@statcan.ca.

\section{REFERENCES}

Angst, J., A. Gamma, L. Pezawas, V. Ajdacic-Gross, D. Eich, W. Rossler et al. 2007."Parsing the Clinical Phenotype of Depression: The Need to Integrate Brief Depressive Episodes." Acta Psychiatrica Scandinavica 115: 221-28.

Cairney, J., B. Veldhuizen, T.J. Wade, P. Kurdyak and D. Streiner. 2007. "Evaluation of 2 Measures of Psychological Distress as Screeners for Depression in the General Population." Canadian Journal of Psychiatry 52: 111-20.

De Marco, R.R. 2000.“The Epidemiology of Major Depression: Implications of Occurrence, Recurrence, and Stress in a Canadian Community Sample." Canadian Journal of Psychiatry 45: 67-74.

Furukawa, T.A., R.C. Kessler, T. Slade and G. Andrews. 2003. “The Performance of the K6 and K10 Screening Scales for Psychological Distress in the Australian National Survey of Mental Health and Well-being." Psychological Medicine 33: 357-62.

Government of Canada. 2007 (March 7). The Budget Plan 2007. Ottawa: Public Works and Government Services Canada.

Kessler, R.C., G. Andrews, L.J. Colpe, R. Hiripi, D.K. Mroczek, S.-L.T. Normand et al. 2002. "Short Screening Scales to Monitor Population Prevalences and Trends in Non-Specific Psychological Distress." Psychological Medicine 32: 959-76.

Kirby, M. and W. Keon. 2006. Out of the Shadows at Last: Transforming Mental Health, Mental Illness and Addiction Services in Canada. Ottawa: Standing Senate Committee on Social Affairs, Science and Technology.

Mathers, C. and D. Loncar. 2006. "Projections of Global Mortality and Burden of Disease from 2002 to 2030." PLoS Medicine 3: 2011-30.

Mojtabai, R. 2005."Trends in Contacts with Mental Health Professionals and Cost Barriers to Mental Health Care among Adults with Significant Psychological Distress in the United States: 1997-2002." American Journal of Public Health 95: 2009-14.

Orpana, H., L. Lemyre and R. Gravel. In review. "The Role of Psychosocial Stressors in Income Disparities in Psychological Distress."

Rhodes, A.E. and K. Fung. 2004. "Self-Reported Use of Mental Health Services versus

Administrative Records: Care to recall?" International Journal of Methods in Psychiatric Research 13: 165-75.

Rust, K. and J. Rao. 1996. "Variance Estimation for Complex Surveys Using Replication Techniques." Statistical Methods in Medical Research 5: 281-310.

Sareen, J., B.J. Cox, T.O. Afifi, I. Clara and B.N. Yu. 2005. “Perceived Need for Mental Health Treatment in a Nationally Representative Canadian Sample." Canadian Journal of Psychiatry 50: 643-51.

Statistics Canada. 2004. "How Healthy Are Canadians? Focus on Mental Health." Health Reports 15: 1-79.

SUDAAN. 2007. Computer program. Research Triangle Park, NC: Research Triangle Institute.

Tambay, J.-L. and G. Catlin. 1995. “Sample Design of the National Population Health Survey - Its Longitudinal Nature." Health Reports 7: 29-38. 


\title{
Online Exclusives
}

\section{Analysis of International Migration Patterns Affecting Physician Supply in Canada}

\author{
Analyse des schémas de migration internationale et de leur influence \\ sur la disponibilité de médecins au Canada
}

MAMORU WATANABE, MELANIE COMEAU AND LYNDA BUSKE

\begin{abstract}
This paper analyzes the migration patterns of both Canadian medical school graduates and international medical graduates (IMGs), and the impact of these patterns on physician supply in Canada. Immigration patterns of IMGs have changed over time, with fewer physicians from the United Kingdom and more from South Africa. A large portion of IMGs who leave Canada (43\%) return "home." Recently, the average duration of practice in Canada for these doctors has been three years, a finding that suggests many came for educational purposes or to acquire skills. The heterogeneity and complexity of international migration are highlighted in this paper.
\end{abstract}

\section{Résumé}

Cet article analyse les schémas de migration des diplômés en médecine d'écoles canadiennes et de ceux venant de l'étranger, et étudie l'impact de ces schémas sur la disponibilité de médecins au Canada. Les schémas d'immigration des diplômés de l'étranger se sont modifiés au cours des années : moins de médecins proviennent du Royaume-Uni et plus viennent de l'Afrique du Sud. Une grande part des diplômés de l'étranger quittent le Canada (43\%) pour retourner au pays où ils ont obtenu leur diplôme. Récemment, le temps moyen de pratique au Canada pour ces médecins était de trois ans, donnée qui suggère que plusieurs d'entre eux sont venus pour obtenir une formation ou acquérir des compétences. L'hétérogénéité et la complexité de la migration internationale sont mis en relief dans l'article.

To view the full article, please visit http://www.longwoods.com/product.php?productid $=19899$ 


\section{Call to Authors}

Data Matters presents brief, focused papers that report analyses of health administrative or survey data that shed light on significant health services and policy issues. Submissions to Data Matters should be a maximum of 1,500 words, exclusive of abstract (max. 100 words), tables, figures and references, and should include no more than three tables or figures.

\section{Appel aux auteurs}

"Questions de données » présente de brefs articles ciblés portant sur des analyses de données administratives ou d'enquêtes sur la santé ou de données d'enquête et qui font la lumière sur d'importantes questions liées aux services et aux politiques de santé. Les articles soumis à "Questions de données » doivent être d'au plus 1500 mots, excluant le résumé (100 mots au plus), les tableaux, diagrammes et références et ne doivent pas comprendre plus de trois tableaux ou diagrammes.

For more information contact Ania Bogacka, Managing Editor, at abogacka@longwoods.com.

Pour de plus amples renseignements, veuillez communiquer avec Ania Bogacka, Directrice de rédaction, à abogacka@longwoods.com.

\section{Listen and learn.}

Longwoods Radio available now at www.longwoods.com

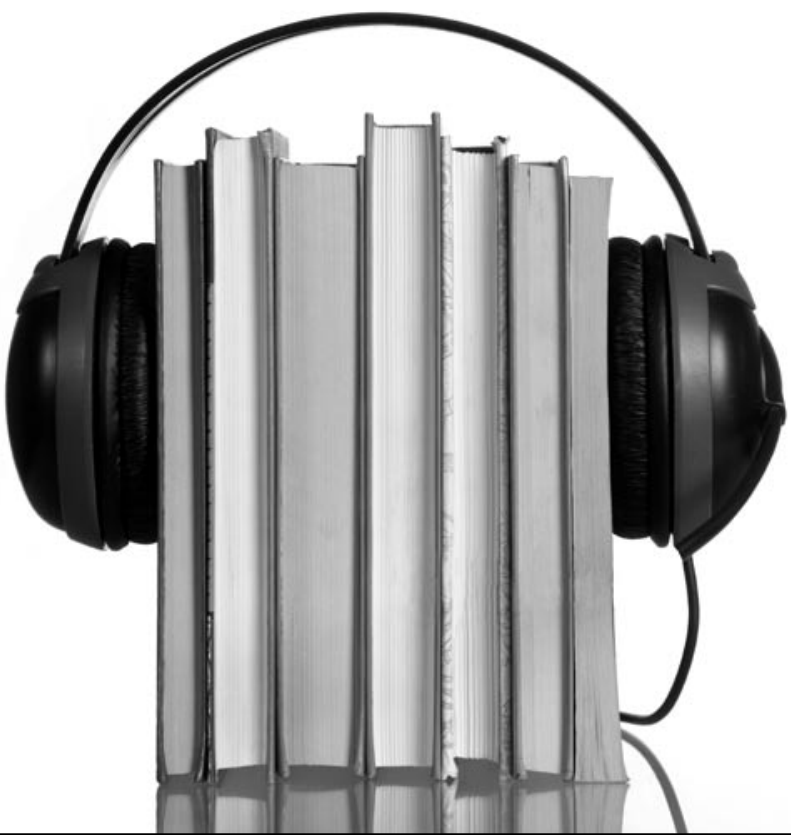

